\title{
Cigarette smoking and risk of colorectal cancer among Norwegian women
}

\author{
Inger T. Gram · Tonje Braaten · Eiliv Lund · \\ Loic Le Marchand · Elisabete Weiderpass
}

Received: 3 October 2008/ Accepted: 24 February 2009/Published online: 10 March 2009

(c) The Author(s) 2009. This article is published with open access at Springerlink.com

\begin{abstract}
Objective The association between cigarette smoking and colorectal cancer (CRC) is still not established. In 2002, Norwegian women had the second highest incidence of CRC in the world. A large proportion of Norwegian women are ever smokers. We examined the association between cigarette smoking and CRC incidence among Norwegian women.

Methods We followed 68,160 women, aged 30-69 years, from the Norwegian Women and Cancer Study who completed a questionnaire in 1996 or 1998 by linkages to national registers through 31 December 2005. Rate ratios (RRs) and 95\% confidence intervals (CIs) were estimated by fitting Cox proportional hazard models. Subsequently, we estimated the population attributable fraction.
\end{abstract}

I. T. Gram $(\bowtie) \cdot$ T. Braaten · E. Lund · E. Weiderpass Institute of Community Medicine, University of Troms $\varnothing$, Breivika, Troms $\varnothing$ N-9037, Norway

e-mail: inger.gram@ism.uit.no

I. T. Gram

Norwegian Centre for Telemedicine, University Hospital of North Norway, Troms $\emptyset$, Norway

\section{Le Marchand}

Cancer Research Center of Hawaii, University of Hawaii, Honolulu, HI, USA

E. Weiderpass

Department of Medical Epidemiology and Biostatistics, Karolinska Institutet, Stockholm, Sweden

\section{E. Weiderpass}

Department of Genetic Epidemiology, Samfundet Folkhälsan (NGO), Helsinki, Finland

\section{E. Weiderpass}

Department of Etiological Research, Cancer Registry of Norway, Oslo, Norway
Results Altogether, 425 incident cases of primary, invasive CRC were identified. Ever smokers had a $20 \%$ increased risk of $\mathrm{CRC}(\mathrm{RR}=1.2 ; 95 \% \mathrm{CI}=1.0-1.5)$, a $30 \%$ increased risk of colon $(\mathrm{RR}=1.3 ; 95 \% \mathrm{CI}=1.0$ $1.7)$, and a $10 \%$ increased risk of rectal $(\mathrm{RR}=1.1 ; 95 \%$ $\mathrm{CI}=0.7-1.5)$ cancer compared to never smokers. The population attributable fraction was estimated to be $12 \%$ which indicated that approximately one in eight of the CRC cases could have been prevented at a population level.

Conclusion Our results support the hypothesis that cigarette smoking is a preventable cause of CRC among women.

Keywords Colorectal cancer - Cigarette smoking · Cohort study · Women · Norway

\section{Introduction}

The association between cigarette smoking and colorectal cancer (CRC) is not established. In Norway, CRC is the second most common cancer found after prostate cancer among men and breast cancer among women with a total of 1,767 incident cases among women in 2006 [1]. For both genders, the age adjusted incidence rate of CRC has been doubled during the last 50 years. In 2002, Norwegian women had the second highest incidence of CRC in the world, only surpassed by women in New Zealand [2].

There has been, so far, no obvious explanation for the increase in risk and top ranking among Norwegian women [3]. Worldwide CRC is one of the most common cancers with a high mortality [2].

In 1996, Giovannucci et al. [4] hypothesized that smoking is an initiator of colorectal carcinogenesis, but that the increased risk only emerges 30-40 years after the smoking initiation. The notion that smoking is a risk factor 
for CRC has been supported by others [5]. However, two reports from 2004, one from the International Agency for Research on Cancer [6] and the other from the US Surgeon General [7], found that there was not enough evidence to conclude that the relationship between smoking and CRC is causal. Because the use of tobacco is rising globally among women $[8,9]$ smoking may result in large numbers of CRCs if a causal association exists.

For more than 30 years, from the late 1960s until the year 2000, the prevalence of daily, current smokers was more than $30 \%$ among Norwegian women. In 2005, daily smokers represented $40 \%$ among those with only primary school education [10]. A large proportion of Norwegian women are ever smokers, i.e., either current or former smokers. Data on smoking and CRC from prospective studies are still sparse. The purpose of this study was to examine the association between cigarette smoking and CRC incidence, overall and by location, in a countrywide, and population-based, prospective cohort study. Subsequently, we estimated the number of avoidable CRCs if no Norwegian women had smoked.

\section{Materials and methods}

\section{Study population-The Norwegian Women and Cancer (NOWAC) study}

As previously documented $[11,12]$ the NOWAC study is a prospective, country wide, and population-based cohort study comprising a representative sample of the Norwegian female population. All women were randomly selected from the Central Population Register according to year of birth. A letter of invitation to participate in the study contained a questionnaire and a pre-stamped return envelope. The National Data Inspectorate and the Regional Committee for Medical Research Ethics approved the study. All women gave an informed consent.

The NOWAC study was initiated in 1991 recruiting 57,600 women aged 34-49 years (response rate 57.6\%) who answered a postal questionnaire. In 1996, women aged 3069 were invited to respond to a postal questionnaire. The cohort expanded with 44,843 women $(56.8 \%$ of the subjects). In 1998, a similar postal questionnaire was mailed to the initial sub-sample, of whom 46,971 women $(81.5 \%)$ responded. More details about the study population may be found elsewhere $[11,12]$ (http://uit.no/kk/NOWAC/).

\section{Exposure information}

The questionnaire included detailed assessment of smoking habits, hormonal contraceptive use, postmenopausal hormone therapy (HT) use, physical activity (PA), and other lifestyle habits as well as height and current weight (allowing us to calculate body mass index (BMI) as weight in kilograms divided by the square of height in meters). It also comprised 82 different food frequency questions including alcohol consumption and dietary supplements.

The questionnaires asked if the women have ever been smoking, and those answering "yes" were asked for number of cigarettes smoked daily at different age intervals. Subsequently, they were asked if they smoke on a daily basis at the moment. We categorized ever smokers according to current and former smoking status, age at smoking initiation, smoking duration, average number of cigarettes smoked daily, pack-years of smoking (i.e., number of cigarettes smoked per day, divided by 20 , multiplied by the number of years smoked), and latency (i.e., age at enrolment in the study minus age at smoking initiation) all at enrolment. Former smokers were classified according to years since quitting smoking. All women not being current or former smokers were classified as never smokers.

Women who reported a natural menopause or a bilateral oophorectomy at cohort enrolment were considered postmenopausal during follow-up. All other women were considered pre-menopausal, regardless of age, hysterectomy, or use of postmenopausal HT. We calculated average daily consumption of alcohol in grams based on the content of pure alcohol in different sorts of beverages among drinkers. Women who reported to be teetotallers and those answering "seldom" or "never" in the frequency table had their alcohol consumption set to zero.

\section{Follow-up and endpoints}

The study population comprised women, aged 30-69 years, who completed a questionnaire in 1996 together with the responders of the second questionnaire in 1998, for a total of 91,814 women. We followed the women with linkages to the Cancer Registry of Norway and the Central Population Register, utilizing the unique national birth number to identify all cancer cases and deaths/emigrations, respectively. The national registries are both accurate and virtually complete [13]. Woman-years were calculated from the start of follow-up to the date of diagnosis of CRC, the date of any incident cancer (except skin basal cell carcinoma) diagnosis, emigration, death, or the end of follow-up, i.e., 31 December 2005, whichever occurred first.

The colorectal tumors were classified according to the Seventh Revision of the International Statistical Classification of Diseases. Women with colon cancer were further categorized according to location of the tumors proximal (codes 153.0/153.1) and distal (codes 153.2/153.3) colon cancers. Tumors that were overlapping (code 153.4), specified as appendix (code 153.6), or unspecified (code 
153.9) were classified as "others" and included in the analyses for the whole colon only.

We excluded 3,734 subjects who were diagnosed with any invasive cancer prior to the start of the study, 17 women who had emigrated or died, one woman with missing vital status, 2,264 women with insufficient information on smoking history, leaving 85,798 women. Altogether 17,638 women, including 116 cases, with missing information for any of the covariates considered a priori as relevant were excluded from the multivariate models. The study population comprised the remaining 68,160 women.

\section{Statistical analysis}

We calculated crude CRC incidence rates by dividing the number of cases by the total number of woman-years in that exposure category. The rates were then age-adjusted to the world standard population [14]. Rate ratios (RRs) and 95\% confidence intervals (CIs) associated with different measures of smoking exposure for CRC overall, and according to location, i.e., in proximal- or distal colon or in rectum, were estimated by fitting Cox proportional hazards models [15] with never smokers as the reference group.

The RR of each of the following factors was estimated in both univariate and multivariate analyses and evaluated as a potential confounder of the relation between cigarette smoking and CRC: age (years, continuous), education (years, continuous), menopausal status (pre, post), both current and ever user of hormonal contraceptive (yes, no), ever user of postmenopausal HT (yes, no), mean recreational and work related PA score on a 10-level scale (110), BMI (continuous), and alcohol consumption (grams/ day), all at enrolment. Several additional dietary factors, i.e., meat, fruit, vegetables, fiber, calcium, and folate, were also evaluated, but none were related to CRC in this cohort and therefore not kept in the final analyses.

Factors changing the RR estimate with $5 \%$ were included in the final multivariate models, i.e., age, menopausal status, ever user of hormonal contraceptive, ever user of postmenopausal hormone therapy, BMI, and alcohol consumption. The Cox analyses were performed with the PHREG procedure in the SAS statistical package [16]. Tests for linear trend were obtained by creating an ordinal exposure variable with equally spaced scores and including it in the models. The population attributable fraction (PAF) was calculated using the formula $\mathrm{PAF}=\frac{P_{\mathrm{e}}\left(R R_{\mathrm{e}}-1\right)}{P_{\mathrm{e}} \times R R_{\mathrm{e}}+\left(1-P_{\mathrm{e}}\right)}$ quoted in Breslow and Day [17], where the notation $P_{\mathrm{e}}=$ The proportion of persons in the population exposed to the risk factor and $R R_{\mathrm{e}}=$ The relative risk in the exposed group compared to the unexposed. All statistical tests were two-sided and were considered statistically significant at $p \leq 0.05$. Finally, we rerun the main analyses in the final models excluding the cases $(n=38)$ which occurred during the first year and also including a category for missing values for each of the covariates. The results did not materially change (data not shown).

\section{Results}

During the 533,786 woman-years of observation, 425 incident cases of histologically confirmed primary invasive colorectal [284 (67\%) colon and $141(33 \%)$ rectal] cancers were identified. Among the colon tumors 137 (48\%) were classified as proximal, $108(38 \%)$ as distal, and the remaining 39 (14\%) cases as "others." Altogether, 43,578 $(64 \%)$ of the women reported to have been ever smokers of which approximately one half $(51 \%)$ reported being current smokers. The proportion of women with a latency period of 30 or more years was higher among the former $(62 \%)$ compared with the current $(59 \%)$ smokers $(p<0.05)$.

Table 1 shows the distribution of selected characteristics at enrolment among cases and non-cases, and according to anatomical distribution of tumors. The cases were older and less educated, and were more likely to be post-menopausal. They were less likely to have a history of ever use of hormonal contraceptive and more likely to have used postmenopausal hormonal therapy compared with noncases (all $p$ values $<0.05$ ). There was no difference between colon and rectal cancer cases or between proximal and distal colon cancer cases for the variables displayed in the table (Table 1).

Table 2 shows that the distribution of the selected characteristics varies according to the women's smoking status. Current smokers differed from never smokers on all the listed variables in Table 2 (all $p$ values $<0.001$ ), except for height. The age-adjusted incidence rates of CRC were 83 and 65 per 100,000 woman-years among ever and never smokers, respectively.

Table 3 shows the multivariate RR estimates of CRC overall and separately for colon and rectal cancers among ever smokers, compared with never smokers. Former smokers had a $30 \%$ increased risk for $\mathrm{CRC}(\mathrm{RR}=1.3$; $95 \% \mathrm{CI}=1.0-1.6)$ and a $40 \%$ increased risk of colon tumors $(\mathrm{RR}=1.4 ; 95 \% \mathrm{CI}=1.1-1.9)$, whereas only nonsignificantly increased risks were found for current smokers. When the two groups were collapsed, ever smokers had a $20 \%$ increased risk of $\mathrm{CRC}(\mathrm{RR}=1.2 ; 95 \%$ $\mathrm{CI}=1.0-1.5)$, a $30 \%$ increased risk of colon cancer $(\mathrm{RR}=1.3 ; 95 \% \mathrm{CI}=1.0-1.7)$, and a non-significantly increased risk of rectal $(\mathrm{RR}=1.1 ; 95 \% \mathrm{CI}=0.7-1.5)$ cancers, compared with never smokers. Ever smokers with a latency period of more than 40 years had a similar $30 \%$ increased risk for colorectal $(\mathrm{RR}=1.3 ; 95 \% \mathrm{CI}=1.0$ $1.7)$, colon $(\mathrm{RR}=1.3 ; 95 \% \mathrm{CI}=0.9-1.8)$, and rectal 
Table 1 Distribution of selected characteristics ${ }^{\mathrm{a}}$ of the study population $(n=68,160)$ at cohort enrolment among cases, non-cases and according to tumor localization

\begin{tabular}{|c|c|c|c|c|c|c|c|c|c|}
\hline Characteristics & $\begin{array}{l}\text { Colorectal } \\
\text { cancer } \\
n=425\end{array}$ & $\begin{array}{l}\text { Non-cases } \\
n=67,735\end{array}$ & $p$-value ${ }^{\mathrm{b}}$ & $\begin{array}{l}\text { Colon } \\
\text { cancer } \\
n=284\end{array}$ & $\begin{array}{l}\text { Rectal } \\
\text { cancer } \\
n=141\end{array}$ & $p$-value ${ }^{c}$ & $\begin{array}{l}\text { Colon } \\
\text { cancer proximal } \\
n=137\end{array}$ & $\begin{array}{l}\text { Colon } \\
\text { cancer distal } \\
n=108\end{array}$ & $p$-value ${ }^{\mathrm{d}}$ \\
\hline Age at enrolment (year) & 55.9 & 49.7 & $<0.0001$ & 56.1 & 55.5 & 0.4 & 57.3 & 55.6 & 0.1 \\
\hline Age at diagnosis (year) & 60.7 & - & - & 61.0 & 60.1 & 0.3 & 61.9 & 60.7 & 0.2 \\
\hline Person years follow-up & 4.6 & 7.9 & $<0.0001$ & 4.7 & 4.4 & 0.4 & 4.5 & 4.9 & 0.2 \\
\hline Education (year) & 10.9 & 11.9 & $<0.0001$ & 10.7 & 11.3 & 0.1 & 10.3 & 10.7 & 0.4 \\
\hline Post-menopausal at enrolment & 62.6 & 35.7 & $<0.0001$ & 62.7 & 62.4 & 1.0 & 64.2 & 64.8 & 0.9 \\
\hline Ever HC use (\%) & 42.4 & 55.9 & $<0.0001$ & 39.1 & 48.9 & 0.0530 & 38.0 & 41.7 & 0.6 \\
\hline Ever PM HT use (\%) & 34.4 & 27.3 & 0.0012 & 36.6 & 29.8 & 0.2 & 38.0 & 38.0 & 1.0 \\
\hline Mean PA score ${ }^{e}$ & 5.4 & 5.5 & 0.4 & 5.4 & 5.3 & 0.9 & 5.2 & 5.6 & 0.2 \\
\hline Body height & 166.0 & 166.1 & 0.7 & 165.8 & 166.6 & 0.1 & 165.2 & 165.7 & 0.5 \\
\hline $\mathrm{BMI}^{\mathrm{f}}$ at enrolment & 24.5 & 24.5 & 0.8 & 24.4 & 24.7 & 0.4 & 24.9 & 24.2 & 0.2 \\
\hline Teetotallers (\%) & 12.5 & 10.6 & 0.2 & 14.4 & 8.5 & 0.1 & 14.6 & 14.8 & 1.0 \\
\hline Alcohol consumption (g/day) $)^{\mathrm{g}}$ & 3.8 & 3.8 & 1.0 & 3.8 & 3.8 & 1.0 & 3.5 & 4.1 & 0.3 \\
\hline
\end{tabular}

Abbreviations: $H C$ Hormonal contraceptive, $P M$ Post-menopausal, $H T$ Hormone therapy, $P A$ Physical activity, $B M I$ Body mass index

${ }^{a}$ Given as mean unless otherwise specified

b $T$-test or chi-square test for differences between cases and non-cases

c $T$-test or chi-square test for differences between colon and rectal cancer cases

${ }^{d} T$-test or chi-square test for differences between proximal and distal colon cancer cases

e Mean recreational and work related physical activity score on a 10-level scale (1-10)

${ }^{\mathrm{f}}$ Body mass index; weight in kilograms divided by the square of the heights in meters

g Among drinkers, g/day $=$ gram per day

Table 2 Distribution of selected characteristics ${ }^{\mathrm{a}}$ of the study population $(n=68,160)$ at cohort enrolment according to smoking status

\begin{tabular}{|c|c|c|c|c|}
\hline Characteristics & $\begin{array}{l}\text { Current smokers } \\
n=22,077\end{array}$ & $\begin{array}{l}\text { Former smokers } \\
\mathrm{n}=21,501\end{array}$ & $\begin{array}{l}\text { Never smokers } \\
n=24,582\end{array}$ & $p$-value ${ }^{\mathrm{b}}$ \\
\hline Age at enrolment (year) & 48.7 & 49.7 & 50.7 & $<0.0001$ \\
\hline Age at diagnosis (year) & 59.5 & 60.5 & 61.9 & 0.0206 \\
\hline Education (year) & 11.2 & 12.1 & 12.5 & $<0.0001$ \\
\hline Post-menopausal at enrolment & 35.0 & 33.9 & 38.5 & $<0.0001$ \\
\hline Age at menopause $(\text { year })^{\mathrm{c}}$ & 47.3 & 48.4 & 49.0 & $<0.0001$ \\
\hline Ever HC use $(\%)$ & 62.3 & 59.2 & 47.0 & $<0.0001$ \\
\hline Ever PM HT use (\%) & 28.6 & 28.8 & 25.0 & $<0.0001$ \\
\hline Mean PA score ${ }^{\mathrm{d}}$ & 5.4 & 5.5 & 5.5 & $<0.0001$ \\
\hline Height (cm) & 166.1 & 166.3 & 166.0 & 0.1 \\
\hline $\mathrm{BMI}$ at enrolment ${ }^{\mathrm{e}}$ & 23.9 & 24.8 & 24.7 & $<0.0001$ \\
\hline Teetotallers $(\%)$ & 5.2 & 6.2 & 19.5 & $<0.0001$ \\
\hline Alcohol consumption $(\mathrm{g} / \mathrm{day})^{\mathrm{f}}$ & 4.1 & 4.1 & 3.2 & $<0.0001$ \\
\hline
\end{tabular}

Abbreviations: HC Hormonal contraceptive, PM Post-menopausal, HT Hormone therapy, PA Physical activity, BMI Body mass index

${ }^{a}$ Given as mean unless otherwise specified

b $T$-test or chi-square test for differences between current and never smokers

c Among women that were postmenopausal at enrolment

${ }^{\mathrm{d}}$ Mean recreational and work related physical activity score on a 10-level scale (1-10)

e $\mathrm{BMI}=$ the weight in kilograms divided by the square of the heights in meters)

f Among drinkers 
Table 3 Multivariate ${ }^{a}$ rate ratios estimates and 95\% confidence intervals of colorectal cancer overall, and by location among ever smokers according to various measures of smoking exposure at enrolment compared with never smokers among 68,160 women

\begin{tabular}{|c|c|c|c|c|c|c|c|c|c|}
\hline & \multicolumn{3}{|c|}{ Colorectal cancer $n=425$} & \multicolumn{3}{|c|}{ Colon cancer $n=284$} & \multicolumn{3}{|c|}{ Rectum cancer $n=141$} \\
\hline & Cases/cohort & RR & $95 \% \mathrm{CI}$ & Cases & $\mathrm{RR}$ & $95 \% \mathrm{CI}$ & Cases & $\mathrm{RR}$ & $95 \% \mathrm{CI}$ \\
\hline \multicolumn{10}{|l|}{ Smoking status } \\
\hline Never & $150 / 24,582$ & 1.0 & Ref & 97 & 1.0 & Ref & 53 & 1.0 & Ref \\
\hline Former & $147 / 21,501$ & 1.3 & $(1.0-1.6)$ & 107 & 1.4 & $(1.1-1.9)$ & 40 & 0.9 & $(0.6-1.4)$ \\
\hline Current & $128 / 22,077$ & 1.2 & $(0.9-1.5)$ & 80 & 1.1 & $(0.8-1.6)$ & 48 & 1.2 & $(0.8-1.8)$ \\
\hline Ever & $275 / 43,578$ & 1.2 & $(1.0-1.5)$ & 187 & 1.3 & $(1.0-1.7)$ & 88 & 1.1 & $(0.7-1.5)$ \\
\hline \multicolumn{10}{|l|}{ Ever smokers } \\
\hline \multicolumn{10}{|c|}{ Smoking initiation } \\
\hline$\geq 20$ & $140 / 17,756$ & 1.2 & $(0.9-1.5)$ & 98 & 1.3 & $(1.0-1.7)$ & 42 & 1.0 & $(0.6-1.5)$ \\
\hline$<20$ & $135 / 25,822$ & 1.3 & $(1.0-1.6)$ & 89 & 1.3 & $(1.0-1.8)$ & 46 & 1.2 & $(0.8-1.8)$ \\
\hline$p$ trend $^{\mathrm{b}}$ & & & $<0.05$ & & & 0.05 & & & 0.5 \\
\hline \multicolumn{10}{|c|}{ Latency (years between smoking initiation and cohort enrolment) } \\
\hline $1-29$ & $55 / 17,249$ & 1.1 & $(0.8-1.5)$ & 37 & 1.2 & $(0.8-1.8)$ & 18 & 0.9 & $(0.5-1.5)$ \\
\hline $30-39$ & $127 / 21,148$ & 1.2 & $(0.9-1.5)$ & 88 & 1.3 & $(1.0-1.8)$ & 39 & 1.0 & $(0.6-1.5)$ \\
\hline$\geq 40$ & $93 / 5,181$ & 1.3 & $(1.0-1.7)$ & 62 & 1.3 & $(0.9-1.8)$ & 31 & 1.3 & $(0.8-2.1)$ \\
\hline$p$ trend $^{\mathrm{b}}$ & & & 0.5 & & & 0.9 & & & 0.3 \\
\hline \multicolumn{10}{|c|}{ Number of cigarettes per day } \\
\hline $1-9$ & $165 / 24,927$ & 1.2 & $(1.0-1.5)$ & 114 & 1.3 & $(1.0-1.7)$ & 51 & 1.0 & $(0.7-1.5)$ \\
\hline $10-14$ & $81 / 12,900$ & 1.3 & $(1.0-1.7)$ & 53 & 1.4 & $(1.0-1.9)$ & 28 & 1.2 & $(0.8-2.0)$ \\
\hline$\geq 15$ & $29 / 5,751$ & 1.1 & $(0.7-1.7)$ & 20 & 1.2 & $(0.7-2.0)$ & 9 & 0.9 & $(0.4-1.9)$ \\
\hline$p$ trend $^{\mathrm{b}}$ & & & 0.14 & & & 0.11 & & & 0.7 \\
\hline \multicolumn{10}{|c|}{ Number of years smoked } \\
\hline $1-19$ & $78 / 15,157$ & 1.1 & $(0.8-1.5)$ & 55 & 1.2 & $(0.9-1.7)$ & 23 & 0.9 & $(0.5-1.5)$ \\
\hline $20-29$ & $66 / 13,592$ & 1.2 & $(0.9-1.6)$ & 47 & 1.4 & $(1.0-2.0)$ & 19 & 0.9 & $(0.5-1.6)$ \\
\hline$\geq 30$ & $131 / 14,829$ & 1.3 & $(1.0-1.6)$ & 85 & 1.3 & $(1.0-1.8)$ & 46 & 1.3 & $(0.8-1.9)$ \\
\hline$p$ trend $^{\mathrm{b}}$ & & & 0.04 & & & 0.07 & & & 0.3 \\
\hline \multicolumn{10}{|c|}{ Number of pack-years smoked } \\
\hline $0-9$ & $113 / 21,609$ & 1.0 & $(0.8-1.3)$ & 78 & 1.1 & $(0.8-1.5)$ & 35 & 0.9 & $(0.6-1.3)$ \\
\hline $10-19$ & $103 / 14,584$ & 1.5 & $(1.1-1.9)$ & 75 & 1.7 & $(1.2-2.3)$ & 28 & 1.1 & $(0.7-1.7)$ \\
\hline$\geq 20$ & $59 / 7,385$ & 1.3 & $(1.0-1.8)$ & 34 & 1.2 & $(0.8-1.8)$ & 25 & 1.5 & $(0.9-2.5)$ \\
\hline$p$ trend $^{\mathrm{b}}$ & & & 0.008 & & & 0.03 & & & 0.13 \\
\hline \multicolumn{10}{|c|}{ Time since quitting smoking (years) } \\
\hline$\geq 20$ & $52 / 6,777$ & 1.1 & $(0.8-1.5)$ & 36 & 1.2 & $(0.8-1.7)$ & 16 & 0.9 & $(0.5-1.6)$ \\
\hline $10-19$ & $46 / 6,122$ & 1.5 & $(1.1-2.1)$ & 24 & 1.7 & $(1.2-2.6)$ & 5 & 1.1 & $(0.6-2.1)$ \\
\hline $1-9$ & $49 / 8,602$ & 1.1 & $(0.8-1.7)$ & 33 & 1.5 & $(1.0-2.4)$ & 13 & 0.5 & $(0.2-1.3)$ \\
\hline 0 (Current) & $128 / 22,077$ & 1.2 & $(1.0-1.5)$ & 84 & 1.2 & $(0.9-1.6)$ & 34 & 1.2 & $(0.8-1.8)$ \\
\hline$p$ trend $^{\mathrm{b}}$ & & & 0.11 & & & 0.16 & & & 0.5 \\
\hline
\end{tabular}

a Adjusted for age, menopausal status, hormonal contraceptive and postmenopausal hormonal therapy use, BMI and alcohol consumption, all at enrolment

b Never smokers included in the model

$(\mathrm{RR}=1.3 ; 95 \% \mathrm{CI}=0.8-2.1)$ cancers. The displayed $\mathrm{RR}$ estimates for smoking initiation $(\geq 20$ and $<20$ years), number of pack-years smoked $(0-9,10-19$, and $\geq 20)$, and duration of smoking (number of years smoked $(1-19,20$ 29 , and $\geq 30)$ ) showed a significant dose response association with colorectal tumors when a category for never smokers was included in the trend test (all $p$ values $<0.05$ ), whereas the number of cigarettes smoked per day did not $(p=0.14)$. Similar significant results were found for colon cancer, while none of the trend tests achieved statistical significance for rectal cancer. The RR estimates for rectal cancer in the upper exposure categories (latency $\geq 40$, smoking initiation $<20$; number of pack-years $\geq 20$, and number of years smoked $\geq 30$ ) were all increased, although 
Table 4 Multivariate $^{\mathrm{a}}$ rate ratios estimates and $95 \%$ confidence intervals for proximal and distal colon cancer according to smoking status among 68,160 women

\begin{tabular}{|c|c|c|c|c|c|c|}
\hline \multirow[t]{2}{*}{ Smoking status } & \multicolumn{3}{|c|}{ Proximal colon cancer $n=137$} & \multicolumn{3}{|c|}{ Distal colon cancer $n=108$} \\
\hline & Cases & $\mathrm{RR}$ & $95 \% \mathrm{CI}$ & Cases & RR & $95 \% \mathrm{CI}$ \\
\hline Never & 44 & 1.0 & Ref & 36 & 1.0 & Ref \\
\hline Former & 53 & 1.6 & $(1.1-2.4)$ & 46 & 1.7 & $(1.1-2.7)$ \\
\hline Current & 40 & 1.4 & $(0.9-2.1)$ & 26 & 1.0 & $(0.6-1.6)$ \\
\hline Ever & 93 & 1.5 & $(1.0-2.2)$ & 72 & 1.3 & $(0.9-2.0)$ \\
\hline
\end{tabular}

${ }^{a}$ Adjusted for age, menopausal status, hormonal contraceptive and postmenopausal hormonal therapy use, BMI and alcohol consumption, all at enrolment

not significantly. No meaningful association was found between time since quitting smoking and colorectal tumors overall or by anatomical subsite (Table 3 ).

Table 4 shows that a model including 137 proximal and 108 distal colon cancers found that former smokers had a significantly increased risk for both the proximal $(\mathrm{RR}=1.6 ; 95 \% \mathrm{CI}=1.1-2.4)$, and distal $(\mathrm{RR}=1.7$; $95 \% \mathrm{CI}=1.1-2.7$ ) colon tumors (Table 4$)$. The PAF was estimated to be $12 \%$.

\section{Discussion}

The results from our study suggest that in Norway one out of eight CRCs would have been prevented annually if women had not been smoking. The increased risk of CRC is found foremost for colon cancer, but is also indicated for rectal cancer. In support of a causal relationship between smoking and CRC, our results show a dose-response relationship between age of smoking initiation, number of years, and of pack-years smoked. The increase in risk of CRC caused by smoking seems to require a long latency period. Thus our results are in accordance with the prevailing hypothesis described previously [4].

Our study has several major strengths. The study is a countrywide, truly population-based, and a prospective cohort representing the general female population in Norway. Also, the smoking histories were obtained at enrolment and, hence, are not subject to recall bias. Our cohort has virtually complete follow-up and we are able to examine the association with smoking according to sitespecific cancer subgroups. We have a high proportion of both current and former smokers [18, 19], and the smoking habits found in our study reflect known smoking patterns among Norwegian women [20]. In addition, we have detailed information on, and are able to control for, established risk factors for $\mathrm{CRC}$, many of which vary according to smoking status. CRC screening practices are not yet common in Norway and are therefore unlikely to affect our results. Furthermore, the cumulative incidence rates during follow-up for all cancer sites have been shown to be almost identical to those reported to the national cancer registries in Norway during the same period [12]. Since our cohort is representative both according to exposure and outcome, we can justify our estimation of PAF due to smoking.

Our study also has several limitations. We have a short follow-up period resulting in a limited number of cases. This gives us more unstable estimates, results that are more prone to chance and we are unable to stratify the analyses in detail according to different measures of smoking exposure. Since time of smoking initiation, latency, duration, and pack-years of smoking are highly correlated; we cannot separate their effects. We lack information on depth of inhalation, type of cigarettes smoked, and passive and occasional smoking status. We assume that women exposed to passive smoking have been included in the reference group. Around 10\% of the Norwegian female population reported to be occasional smokers at the period of our enrolment of whom approximately half were former daily smokers [20]. We believe that in our study, some of these women have been excluded due to insufficient smoking information; some have been included in the reference group, while those answering "yes" to ever and "no" to current daily smoking have been classified as former smokers. Including women exposed to passive smoking and those who smoke occasionally in the reference group would have attenuated the associations between smoking and CRC. Categorizing occasional smokers as former smokers would most likely have the same effect. A limitation is that we do not have information on changes in smoking habits during follow-up. However, few Norwegian women start to smoke after the age of 30 , which is the lowest age of enrolment in our study. We know that current smokers quit smoking and former smokers reengaged in smoking [20]. If a large proportion of the ever smoking women changed exposure category during follow-up, this would have resulted in an underestimation of the RR among current and an overestimation of the RR among former smokers. Since current smokers have an increased risk of dying from any major cause during follow-up and $\mathrm{CRC}$ is assumed to take many years, competing causes of 
death may decrease the impact of smoking among current smokers. Both circumstances could explain why the association with $\mathrm{CRC}$ is quite similar for current and former smokers. In the multivariate analysis, alcohol consumption was the covariant with most impact on the RR estimates. We lack information on changes regarding the covariates during the follow-up. There may be some residual confounding due to these and other unknown risk factors. Nevertheless, the dose response observed is suggestive of a causal association.

In the latest review by the International Agency for Research on Cancer in 2004 [6], most of the studies examined for a possible causal relationship between smoking and risk of CRC did not have the required hypothesized latency or induction period. The results from the few previous epidemiological studies finding weak positive associations between smoking and CRC have been explained as confounded by alcohol and other dietary risk factors [6, 21]. Indeed both, alcohol consumption [22, 23] and intake of read meat [23] were recently established as risk factors for CRC.

In Norway, women began smoking in substantial numbers in the late 1960s and early 1970s [10]. As a consequence our cohort study is the first in which a high proportion of Norwegian women could have accrued long enough induction time for the smoking and $\mathrm{CRC}$ relationship to take place. Nevertheless, a previous study from Norway, including older cohorts with fewer smoking women, did find a non-significant increased risk of both colon and rectal cancer among former, but not among current smoking women [24].

It has been suggested that colon and rectal cancer may have different risk factors [25]. Our results indicate that smoking is a risk factor for both proximal and distal colon cancer as well as for rectal cancer. The association is more consistent for colon cancer, which may be due to the fact that we had twice as many colon cancers as rectal cancer cases. We find the overall associations to be similar among former and current smokers. We find no association between time since smoking cessation and risk of CRC. These results are consistent with the hypothesis that smoking is an initiator rather than a promoter of CRC [26, 27].

Results from other cohort studies are sparse and somewhat inconsistent, and they do not represent the general population as ours do. In 1994, Giovannucci et al. [26] reported that ever smokers in the Nurses' Health Study had an increase in risk of both colon and rectal cancer and that most importantly this increase in risk was not revealed until 35 years after smoking had begun. Using data from the Canadian National Breast Cancer Study, Terry et al. [28] found a significantly increased risk of rectal cancer, but not of colon cancer among women with a smoking latency of more than 40 years. The Iowa Women's Health Study found that ever smokers among the postmenopausal women had an overall increased risk of CRC [29]. In a recent report examining the participants in the Women's Health Initiative study, Paskett et al. [30] found a statistically significant increased risk among the less than seven percent current smokers for rectal cancer, but not for colon cancer. Among the approximately $42 \%$ former smokers the results showed a borderline significantly increased risk of $12 \%$ for colon cancer, and a non-significant increased risk of $15 \%$ for rectal cancer.

Two European cohort studies [31, 32], also found an increased risk for CRC overall. The Swedish study reported that after examining the relationship by subsite, ever smokers had a $60 \%$ non-significant increased risk for colon $(n=318)$ and a fivefold increased risk for rectal cancer which almost all of the 180 cases occurred among the men [31]. The other study from the UK only included 95 cases and did not report by subsite [32]. These results were, as ours, from multivariate analyses adjusting for, among other factors and intake of alcohol [26, 28-32]. In a recent report from the US [33], examining two cohorts from 1963 to 1975 with both genders, a non-significant increased risk for rectal cancer was found among women in the most recent cohort. This study based on data from two private censuses could only adjust for a few socioeconomic factors.

Some of the case-control studies that show results for women separately have found a positive relationship between ever smoking and colon cancer, but not rectal cancer [34] for rectal, but not colon cancer [35], and for both [36] cancers. In a systematic review including six cohort and 15 case-control studies in Japan, the authors conclude that ever smokers may have an increased risk for $\mathrm{CRC}$, and particularly for rectal cancer. The few results displayed for women were in agreement with this [37]. Several recent studies have examined if the relatively weak association between smoking and CRC is depending on genetic susceptibility [38] or on molecular aspects of the tumor [39, 40]. So far no clear pattern has emerged.

Cigarette smoking has been shown to be a precursor for colorectal adenomas which are established risk factors for CRC [41, 42]. Cigarette smoke contains a mixture of at least 60 established mutagenic carcinogens including arsenic, cadmium, ammonia, formaldehyde, and benzopyrene [6]. These and other genotoxic compounds, including polynuclear aromatic hydrocarbons, heterocyclic amines, nitrosamines, and aromatic amines may reach the colorectal mucosa through direct ingestion or through the blood stream [27]. Presence of anti-benzo(a)pyrene diolepoxide-DNA adduct formation in human colon mucosa have been suggested as an evidence of a direct carcinogenic effect on the colon derived from diet/and or tobacco smoke [43]. Ben$\mathrm{zo}(\mathrm{a})$ pyrene $[\mathrm{B}(\mathrm{a}) \mathrm{p}]$ is an incomplete combustion product 
from cigarette smoke that has been shown to have powerful carcinogenic activity and to act locally. Hecht has recently published a model for understanding the mechanisms of tobacco carcinogenesis. This model conceptualizes the complex pathways that lead to genomic instability and ultimately to cancer due to persistence of un-repaired DNA adducts in tissues of people who smoke cigarettes [44, 45]. The above listed carcinogens in tobacco smoke are plausible risk factors for colorectal carcinogenesis and support the biological plausibility of a positive association between smoking and CRC.

The smoking epidemic among women in the last four decades can explain some of the marked increase in incidence of CRC in Norway. In conclusion, our results support the hypothesis that cigarette smoking is a preventable cause of CRC among women.

Acknowledgments This work was carried out while Professor Gram was a Visiting Scholar at the Cancer Research Center of Hawaii, University of Hawaii. No funding was received for this study. Authors declare no commercial or other associations that might pose a conflict of interest in relation to this manuscript.

Open Access This article is distributed under the terms of the Creative Commons Attribution Noncommercial License which permits any noncommercial use, distribution, and reproduction in any medium, provided the original author(s) and source are credited.

\section{References}

1. Cancer Registry of Norway (2007) Cancer in Norway 2006cancer incidence, mortality. Cancer Registry of Norway, Oslo

2. Ferlay J, Bray F, Pisani P, Parkin DM (2004) GLOBOCAN 2002: cancer incidence, mortality and prevalence worldwide. IARC Cancer Base No. 5 [2.0]. IARC Press, Lyon

3. Bray F, Wibe A, Dorum LM, Moller B (2007) Epidemiology of colorectal cancer in Norway. Tidsskr Nor Laegeforen 127:26822687

4. Giovannucci E, Martinez ME (1996) Tobacco, colorectal cancer, and adenomas: a review of the evidence. J Natl Cancer Inst 88:1717-1730. doi:10.1093/jnci/88.23.1717

5. Potter JD (1999) Colorectal cancer: molecules and populations. J Natl Cancer Inst 91:916-932. doi:10.1093/jnci/91.11.916

6. International Agency for Research on Cancer (2004) IARC monographs on the evaluation of carcinogenic risks to humans. Tobacco smoke and involuntary smoking, vol 83. IARC Press, Lyon

7. Department of Health, Human Services, Center for Disease Control, Prevention (2004) The health consequences of smoking: a report of the Surgeon General. Center for Disease Control and Prevention, Washington DC

8. World Health Organization (2001) Women and the tobacco epidemic: challenges for the 21st century. The World Health Organization, Geneva

9. World Health Organization (2008) WHO report on the global tobacco epidemic, 2008: the MPOWER package. World Health Organization, Geneva

10. Ministry of Health and Care Services (2007) Norway's national strategy for tobacco control 2006-2010. I-1112 B. Ministry of Health and Care Services, Oslo
11. Lund E, Kumle M, Braaten T et al (2003) External validity in a population-based national prospective study-the Norwegian Women and Cancer Study (NOWAC). Cancer Causes Control 14:1001-1008. doi:10.1023/B:CACO.0000007982.18311.2e

12. Lund E, Dumeaux V, Braaten T et al (2008) Cohort profile: the Norwegian women and cancer study-NOWAC-Kvinner og kreft. Int J Epidemiol 37:36-41. doi:10.1093/ije/dym137

13. Lund E (1981) Pilot study for the evaluation of completeness of reporting to the cancer registry. Incidence of cancer in Norway, 1978. Cancer Registry of Norway, Oslo, pp 11-14

14. Parkin DM, Whelan SL, Ferlay J, Teppo L, Thomas DB (2002) Cancer incidence in five continents, vol 8. IARC, Lyon

15. Cox DR (1972) Regression models and life-tables. J R Stat Soc B34:187-220

16. SAS (1999) SAS/STAT user's guide, 8th edn. SAS Institute Inc., Cary, NC

17. Breslow NE, Day NE (1980) Statistical methods in cancer research. The analysis of case-control studies, vol 1. International Agency for Research on Cancer, Lyon

18. Gram IT, Braaten T, Terry PD (2005) Breast cancer risk among women who start smoking as teenagers. Cancer Epidemiol Biomarkers Prev 14:61-66

19. Gram IT, Braaten T, Adami HO, Lund E, Weiderpass E (2008) Cigarette smoking and risk of borderline and invasive epithelial ovarian cancer. Int J Cancer 122:647-652. doi:10.1002/ijc.23108

20. Lindbak R (1999) Tall om tobakk 1973-1998. Statens tobakkskaderåd, Oslo

21. Vineis P, Alavanja M, Buffler P et al (2004) Tobacco and cancer: recent epidemiological evidence. J Natl Cancer Inst 96:99-106

22. Baan R, Straif K, Grosse Y et al (2007) Carcinogenicity of alcoholic beverages. Lancet Oncol 8:292-293. doi:10.1016/ S1470-2045(07)70099-2

23. World Cancer Research Fund/American Institute for Cancer Research (2007) Food, nutrition, physical activity, and the prevention of cancer: a global perspective. AICR, Washington DC

24. Engeland A, Andersen A, Haldorsen T, Tretli S (1996) Smoking habits and risk of cancers other than lung cancer: 28 years' follow-up of 26,000 Norwegian men and women. Cancer Causes Control 7:497-506. doi:10.1007/BF00051881

25. Wei EK, Giovannucci E, Wu K et al (2004) Comparison of risk factors for colon and rectal cancer. Int J Cancer 108:433-442. doi:10.1002/ijc. 11540

26. Giovannucci E, Colditz GA, Stampfer MJ et al (1994) A prospective study of cigarette smoking and risk of colorectal adenoma and colorectal cancer in US women. J Natl Cancer Inst 86:192-199. doi:10.1093/jnci/86.3.192

27. Giovannucci E (2001) An updated review of the epidemiological evidence that cigarette smoking increases risk of colorectal cancer. Cancer Epidemiol Biomarkers Prev 10:725-731

28. Terry PD, Miller AB, Rohan TE et al (2002) Prospective cohort study of cigarette smoking and colorectal cancer risk in women. Int J Cancer 99:480-483. doi:10.1002/ijc.10364

29. Limburg PJ, Vierkant RA, Cerhan JR et al (2003) Cigarette smoking and colorectal cancer: long-term, subsite-specific risks in a cohort study of postmenopausal women. Clin Gastroenterol Hepatol 1:202-210. doi:10.1016/S1542-3565(03)70037-8

30. Paskett ED, Reeves KW, Rohan TE et al (2007) Association between cigarette smoking and colorectal cancer in the Women's Health Initiative. J Natl Cancer Inst 99:1729-1735. doi: 10.1093/jnci/djm176

31. Terry P, Ekbom A, Lichtenstein P, Feychting M, Wolk A (2001) Long-term tobacco smoking and colorectal cancer in a prospective cohort study. Int J Cancer 91:585-587. doi:10.1002/1097-0215 (200002)9999:9999<::AID-IJC1086>3.0.CO;2-H

32. Sanjoaquin MA, Appleby PN, Thorogood M, Mann JI, Key TJ (2004) Nutrition, lifestyle and colorectal cancer incidence: a 
prospective investigation of 10998 vegetarians and non-vegetarians in the United Kingdom. Br J Cancer 90:118-121. doi: 10.1038/sj.bjc.6601441

33. Hooker CM, Gallicchio L, Genkinger JM, Comstock GW, Alberg AJ (2008) A prospective cohort study of rectal cancer risk in relation to active cigarette smoking and passive smoke exposure. Ann Epidemiol 18:28-35. doi:10.1016/j.annepidem.2007.06.010

34. Slattery ML, Samowtiz W, Ma K et al (2004) CYP1A1, cigarette smoking, and colon and rectal cancer. Am J Epidemiol 160:842852. doi:10.1093/aje/kwh298

35. Newcomb PA, Storer BE, Marcus PM et al (1995) Cigarette smoking in relation to risk of large bowel cancer in women. Cancer Res 55:4906-4909

36. Luchtenborg M, White KK, Wilkens L, Kolonel LN, Le Marchand L (2007) Smoking and colorectal cancer: different effects by type of cigarettes? Cancer Epidemiol Biomarkers Prev 16:1341-1347. doi:10.1158/1055-9965.EPI-06-0519

37. Mizoue T, Inoue M, Tanaka K et al (2006) Tobacco smoking and colorectal cancer risk: an evaluation based on a systematic review of epidemiologic evidence among the Japanese population. Jpn J Clin Oncol 36:25-39. doi:10.1093/jjco/hyi207

38. Stern MC, Conti DV, Siegmund KD et al (2007) DNA repair singlenucleotide polymorphisms in colorectal cancer and their role as modifiers of the effect of cigarette smoking and alcohol in the Singapore Chinese Health Study. Cancer Epidemiol Biomarkers Prev 16:2363-2372. doi:10.1158/1055-9965.EPI-07-0268
39. Luchtenborg M, Weijenberg MP, Kampman E et al (2005) Cigarette smoking and colorectal cancer: APC mutations, hMLH1 expression, and GSTM1 and GSTT1 polymorphisms. Am J Epidemiol 161:806-815. doi:10.1093/aje/kwi114

40. Samowitz WS, Albertsen H, Sweeney C et al (2006) Association of smoking, CpG island methylator phenotype, and V600E BRAF mutations in colon cancer. J Natl Cancer Inst 98:1731-1738

41. Giovannucci E (2004) Should smokers be considered a high-risk group for colorectal cancer? Dig Liver Dis 36:643-645. doi: 10.1016/j.dld.2004.06.012

42. Shrubsole MJ, Wu H, Ness RM, Shyr Y, Smalley WE, Zheng W (2008) Alcohol drinking, cigarette smoking, and risk of colorectal adenomatous and hyperplastic polyps. Am J Epidemiol 167:1050-1058. doi:10.1093/aje/kwm400

43. Alexandrov K, Rojas M, Kadlubar FF, Lang NP, Bartsch H (1996) Evidence of anti-benzo[a]pyrene diolepoxide-DNA adduct formation in human colon mucosa. Carcinogenesis 17:2081-2083. doi:10.1093/carcin/17.9.2081

44. Hecht SS (2006) Cigarette smoking: cancer risks, carcinogens, and mechanisms. Langenbecks Arch Surg 391:603-613. doi: 10.1007/s00423-006-0111-z

45. Hecht SS (2008) Progress and challenges in selected areas of tobacco carcinogenesis. Chem Res Toxicol 21:160-171. doi: $10.1021 /$ tx 7002068 